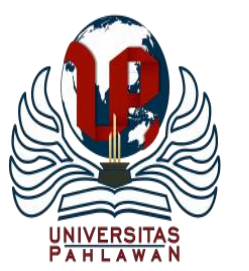

Jurnal Abdidas Volume 2 Nomor 5 Tahun 2021 Halaman 1120 - 1126

JURNAL ABDIDAS

http://abdidas.org/index.php/abdidas

\title{
Penyuluhan Tentang Makanan yang Dianjurkan untuk Anak Berkebutuhan Khusus (ABK) Hiperaktif
}

\author{
Maria Widijanti Sugeng ${ }^{1 凶}$, Retno Dwi Wulandari ${ }^{2}$, Eva Diah Setijowati ${ }^{3}$ \\ Fakultas Kedokteran, Universitas Wijaya Kusuma Surabaya, Indonesia ${ }^{1,2,3}$ \\ E-mail: mariasugeng19@gmail.com¹, retno_dwi_w@yahoo.com ${ }^{2}$, evaerwin_yul1anto@yahoo.co.id ${ }^{3}$
}

\begin{abstract}
Abstrak
Banyak Anak Berkebutuhan Khusus (ABK) mempunyai gejala hiperaktif. Gejala ini sangat mengganggu proses belajar baik di sekolah maupun di rumah. Hiperaktifitas berkaitan dengan gangguan konsentrasi dan kemampuan untuk memahami materi pelajaran. Beberapa penelitian menyebutkan bahwa ada hubungan antara makanan yang dikonsumsi ABK dengan gejala hiperaktifitas. Bahan makanan dapat mempengaruhi fungsi otak yang berkaitan dengan hiperaktifitas, pola tidur, kemampuan kognitif dan suasana hati (mood) seseorang. Berdasarkan latar belakang di atas, maka penyuluhan tentang makanan yang seharusnya diberikan untuk orang tua atau pihak yang bertanggungjawab menyediakan makanan untuk Anak Berkebutuhan Khusus (ABK) dengan tipe hiperaktif. Berkaitan dengan kondisi Pandemi Covid 19, maka penyuluhan ini dilakukan secara daring pada 98 peserta webinar yang terdiri dari orang tua $\mathrm{ABK}$, orang tua non $\mathrm{ABK}$, pengasuh anak, guru $\mathrm{ABK}$, guru non $\mathrm{ABK}$, mahasiswa jurusan kesehatan dan lain-lain. Dari hasil pos tes yang dilakukan sekitar $68 \%$ peserta bisa menjawab dengan benar pertanyaan seputar makanan yang dianjurkan untuk ABK yang hiperaktif. Semua peserta menjawab penyuluhan daring tentang nutrisi pada ABK hiperaktif ini bermanfaat.
\end{abstract}

Kata kunci: penyuluhan daring, nutrisi ABK hiperaktif, post- tes

\begin{abstract}
Many children with special needs (ABK) have symptoms of hyperactivity. These symptoms greatly interfere with the learning process both at school and at home. Hyperactivity is concerned with impaired concentration and the ability to understand learning materials Some studies mention that there is a relationship between the food consumed by children with symptoms of hyperactivity. Food affect brain function related to hyperactivity, sleep patterns, cognitive ability and mood of a person. Based on the background above, then lecture about the food that should be given to parents or helpers that responsible for preparing food for Children with Special Needs (ABK) with hyperactive type. Due to Covid 19 pandemic, this online seminar was conducted to 98 webinar participants that consist of $A B K$ parents, non-ABK parents, babysitters, $A B K$ and non-ABK teachers and health majoring students. From the results of the post test conducted about 68\% of participants were able to answer correctly about foods that are recommended for hyperactive children. All participants answered that this online seminar about nutrition in hyperactive children is beneficial.
\end{abstract}

Keywords: online seminar, nutrition for hyperactive children, post test

Copyright (c) 2021 Maria Widijanti Sugeng, Retno Dwi Wulandari, Eva Diah Setijowati

$\checkmark$ Corresponding author

Address : Fakultas Kedokteran UWKS

Email : mariasugeng19@gmail.com

DOI $\quad:$ https://doi.org/10.31004/abdidas.v2i5.424

ISSN 2721- 9224 (Media Cetak)

ISSN 2721- 9216 (Media Online) 
1121 Penyuluhan Tentang Makanan yang Dianjurkan untuk Anak Berkebutuhan Khusus (ABK) Hiperaktif Maria Widijanti Sugeng, Retno Dwi Wulandari, Eva Diah Setijowati

DOI: https://doi.org/10.31004/abdidas.v2i5.424

\section{PENDAHULUAN}

Makanan berpengaruh terhadap fungsi otak, terutama pada anak-anak. Makanan dan nutrisi yang terkandung di dalamnya mempengaruhi fungsi kognisi, kemampuan untuk memperhatikan (atensi), pola tidur dan suasana hati (mood). Orang-orang yang mengkonsumsi makanan yang "sehat" atau banyak sayuran, buah-buahan, bijibijian yang tidak diproses dan daging rendah lemak mempunyai kesehatan mental yang lebih baik serta kecenderungan untuk mengalami gangguan suasana hati (mood disorders) lebih rendah 25 sampai 35 persen (Selhub, 2015). Banyak orang tua yang mempunyai anak dengan Attention Deficit Hyperactivity Disorder (ADHD) melaporkan bahwa bahan-bahan makanan tertentu berpengaruh terhadap hiperaktivitas anak-anak mereka (Schab \& Trinh, 2004).

\section{Pengertian Hiperaktif pada Anak}

Pada umumnya anak yang hiperaktif memiliki kondisi yang disebut ADHD atau Attention-deficit hyperactivity disorder, adalah gangguan jangka panjang (lebih dari 6 bulan) yang biasanya menyerang anak-anak yang telah dideteksi sebelum umur 7 tahun berupa perilaku impulsif, kegiatan motorik yang berlebihan (hiperaktif), cemas, dan mudah teralihkan atau rendahnya kemampuan untuk memperhatikan. Seringkali disertai juga dengan perkembangan emosi yang terlambat, sifat agresif, dan kemampuan akademik yang buruk (Barkley, 2014).

Penyebabnya masih belum diketahui, diduga berkaitan dengan faktor genetik dan lingkungan. Meskipun ADHD umumnya ditemukan pada anak- anak, gejala yang ditimbulkan dapat menetap hingga masa remaja dan dewasa (Barkley, 2014).

\section{Pengaruh Nutrisi pada Otak}

Nutrisi pada bahan makanan mempengaruhi kerja otak. Sel-sel otak seperti sel-sel tubuh lainnya memerlukan nutrisi yang tepat untuk menjalankan fungsinya makanan yang tepat bila diberikan pada seseorang dengan ADHD bisa mengoptimalkan fungsi otak. Beberapa bahan makanan seperti karbohidrat simpleks (refined sugar), bahan pewarna dan pengawet makanan artifisial (food addtives) serta asam lemak esensial bisa mempengaruhi aktivitas elektrik otak dan pembentukan neurotransmiter seperti dopamin, serotonin dan norefineprin (Lange, 2020).

\section{Pewarna Makanan Artifisial}

Pewarna makanan artifisial seperti sunset yellow, carmoisine, tartrazine, ponceau 4R, quinolone yellow dan allura red AC dapat meningkatkan hiperaktivitas pada anak-anak kelompok usia 3 tahun (kelompok pra sekolah) dan kelompok usia 8-9 tahun (kelompok Sekolah Dasar) di Inggris (McCann et al., 2007). Penelitian serupa juga menemukan bahwa menghilangkan pewarna makanan artifisial dari makanan anak dengan ADHD sebanding dengan sepertiga sampai setengah efek terapi methylphenidate (Ritalin) (Schab \& Trinh, 2004).

Hipotesa mengenai pengaruh pewarna dan pengawet makanan (food additives) serta makanan yang mengandung salisilat terhadap tingkah laku hiperaktif pada anak-anak diperkenalkan oleh Feingold. Dari hasil observasinya, Feingold 
1122 Penyuluhan Tentang Makanan yang Dianjurkan untuk Anak Berkebutuhan Khusus (ABK) Hiperaktif Maria Widijanti Sugeng, Retno Dwi Wulandari, Eva Diah Setijowati

DOI: https://doi.org/10.31004/abdidas.v2i5.424

mengatakan bahwa sekitar 50\% anak-anak yang hiperaktif mengalami perbaikan setelah anak-anak tersebut menghindari makanan dengan food additives dan salisilat (Feingold, 1985). Makanan dengan artificial food additives seperti pewarna, pengawet dan tambahan rasa banyak dijumpai pada makanan ringan (snack) dan minuman ringan yang diproses di pabrik seperti jus, minuman soda serta makanan proses lainnya seperti ham, sosis, bacon dan makanan kaleng lainnya (Schab \& Trinh, 2004).

\section{Pengawet Makanan}

Pengawet makanan seperti sodium benzoate pada penelitian di Inggris juga meningkatkan hiperaktivitas anak usia 3,8 dan 9 tahun. Hiperaktivitas pada kelompok anak yang usianya lebih kecil (kelompok usia 3 tahun) ditemukan lebih tinggi dibandingkan pada kelompok anak yang lebih besar (kelompok usia 8-9 tahun) (McCann et al., 2007).

\section{Bahan Makanan Mengandung Salisilat}

Beberapa bahan makanan mengandung salisilat secara alami, contohnya almond, apel, apricot, buah beri, cheri, kopi, teh, menitimun, acar, anggur dan kismis, nektarin dan jeruk, peach, paprika, plum,dan tomat. Salisilat diproduksi oleh tumbuhan untuk mempertahankan diri dari serangga, fungus dan penyakit. Dalam sehari ratarata orang mengkonsumsi salisilat dalam bahan makanan sekitar 10-200 mg (Cunningham, 2010).

Beberapa orang mempunyai reaksi alergi (intoleran) terhadap bahan-bahan makanan yang mengandung salisilat. Hipersensitivitas terhadap salisilat lebih sering ditemukan pada penderita asma yaitu sekitar 2-22\% (Park et al., 2013). Penyebabnya tidak diketahui, diperkirakan disebabkan oleh produksi yang berlebihan dari leukotrin, mediator inflamasi yang berkaitan dengan penyakit autoimun seperti asma, rheumatoid arthritis dan inflammatory bowel disease (Sharma \& Mohammed, 2006).

Bahan makanan yang mengandung salisilat alami sangat banyak, sehingga susah untuk menerapkan diet tanpa salisilat. Pada penelitian case control yang dilakukan di Sydney menunjukkan bahwa diet tanpa salisilat tidak menunjukkan hasil yang signifikan untuk mengurangi gejala hiperaktif atau gejala alergi lain, bahkan bisa memberikan efek samping kekurangan nutrisi lain (Gray et al., 2013).

\section{Gula dan Pemanis Buatan}

Penelitian di University of South Carolina menyimpulkan bahwa semakin banyak gula yang dikonsumsi anak yang hiperaktif (dengan ADHD), semakin gelisah dan aktif anak tersebut. Pemelitian ini dilakukan pada 28 anak usia 4-7 tahun dengan ADHD dan 26 anak normal sebagai kontrol. Mereka diobservasi selama 7 hari (Prinz et al., 1980). Prinz dan Riddle (1986) juga meneliti pengaruh konsumsi gula pada anak yang tidak hiperaktif, yang diobservasi selama 1 minggu. Kelompok anak yang mengkonsumsi banyak gula (di atas $5.47 \mathrm{~g} / \mathrm{kg}$ berat badan) tidak bisa konsentrasi (fokus) dalam waktu lama, dibandingkan dengan mereka yang mengkonsumsi gula lebih sedikit (kurang dari $3,23 \mathrm{~g} / \mathrm{kg}$ berat 
1123 Penyuluhan Tentang Makanan yang Dianjurkan untuk Anak Berkebutuhan Khusus (ABK) Hiperaktif Maria Widijanti Sugeng, Retno Dwi Wulandari, Eva Diah Setijowati

DOI: https://doi.org/10.31004/abdidas.v2i5.424

badan) (Prinz \& Riddle, 1986). Penelitian di Yale juga mengindikasikan bahwa diet tinggi gula bisa meningkatkan gangguan untuk memperhatikan pada anak dengan ADHD (Jones et al., 1995).

\section{Mikronutrien}

Mikronutrien adalah zat-zat makanan yang diperlukan tubuh dalam jumlah kecil dan tidak dapat diproduksi oleh tubuh itu sendiri, contohnya vitamin, mineral dan asam lemak tidak jenuh/polyunsaturated fatty acids (PUFAs). Beberapa mikronutrien yang sering ditemukan defisiensi pada anak-anak dengan ADHD adalah besi, seng (zinc), magnesium dan vitamin B6, meskipun beberapa penelitian tentang kaitan mikronutrien dengan gejala ADHD hasilnya bervariasi Pemberian vitamin dan mineral dalam jumlah besar bisa berakibat toksik (Lange, 2020).

Asam lemak tidak jenuh terutama asam lemak esensial penting untuk meningkatkan fungsi sel, imunitas secara umum, dan kesehatan jantung. Tubuh tidak bisa membentuk asam lemak esensial, jadi nutrisi ini harus diperoleh dari makanan. Contoh asam lemak esensial adalah asam lemak omega 3 dan 6. Asam lemak omega 3 eicosapentaenoic acid (EPA), docosahexaenoic acid (DHA), dan andarachidonic acid (AA), biasanya didapat dari ikan salmon, tuna, cod atau ikan air dingin lainnya serta biji-bijian dan minyak biji-bijian. Sedangkan asam lemak omega 6 seperti asam linoleic biasanya diperoleh dari minyak sayur. Nutrisi yang seimbang antara omega 3 dan 6 adalah yang terbaik untuk kesehatan secara keseluruhan (Freeman et al., 2006).
Pada anak-anak dengan ADHD ditemukan bahwa kadar omega 3 terutama docosahexaenoic acid (DHA), eicosapentaenoic acid (EPA) dan arachidonic acid (AA) menurun secara signifikan dibandingkan dengan anak-anak normal. Defisiensi omega 3 dikatakan berkaitan dengan gejala ADHD karena omega 3 berkaitan dengan transmisi neurotransmitter dopamin dan serotonin serta membantu sel-sel otak untuk berinteraksi (Freeman et al., 2006). Dikatakan juga bahwa terjadi perubahan atau gangguan metabolisme asam lemak pada anak-anak dengan ADHD (Stevens et al., 1995). Menurut Kane (1999) anakanak dengan ADHD yang diberi suplemen asam lemak spesifik sesuai dengan defisiensi yang mereka derita akan menunjukkan perbaikan sikap (Kane, 1999).

\section{METODE}

Rencana awal penyuluhan ini adalah penyuluhan luring di sebuah Sekolah Informal di Surabaya yang mempunyai banyak siswa ABK. Berhubung adanya Pandemi Covid 19, penyuluhan luring tidak mungkin dilakukan. Alternatifnya adalah penyuluhan daring dengan menggunakan Zoom. Materi penyuluhan tentang bahan-bahan makanan yang dapat mengurangi dan memperberat gejala hiperaktifitas pada ABK. Setelah penyuluhan dilakukan pos tes untuk mengetahui tingkat pengetahuan orang tua mengenai materi yang diberikan. Urutan acara penyuluhan sebagai berikut: 
1124 Penyuluhan Tentang Makanan yang Dianjurkan untuk Anak Berkebutuhan Khusus (ABK) Hiperaktif Maria Widijanti Sugeng, Retno Dwi Wulandari, Eva Diah Setijowati

DOI: https://doi.org/10.31004/abdidas.v2i5.424

Tabel 1. Urutan Acara Seminar Luring

\begin{tabular}{|l|l|l|l|}
\hline No & TAHAP & $\begin{array}{l}\text { WAK } \\
\text { TU }\end{array}$ & KEGIATAN PENYULUHAN \\
\hline 1. & $\begin{array}{l}\text { Pembu-- } \\
\text { kaan }\end{array}$ & 5 menit & $\begin{array}{l}\text { Perkenalan Pembicara } \\
\text { Menjelaskan latar belakang dan } \\
\text { tujuan penyuluhan }\end{array}$ \\
\hline 2. & $\begin{array}{l}\text { Pemberian } \\
\text { Materi }\end{array}$ & 25 menit & $\begin{array}{l}\text { Memberikan edukasi dan tambahan } \\
\text { pengetahuan tentang nutrisi pada } \\
\text { ABK hiperaktif }\end{array}$ \\
\hline 3. & Evaluasi & 20 menit & Tanya jawab. \\
\hline 4. & Penutup & 5 menit & Menyimpulkan hasil penyuluhan. \\
\hline 5. & Pos tes & 5 menit & $\begin{array}{l}\text { Mengukur tingkat pengetahuan } \\
\text { orang tua ABK setelah penyuluhan }\end{array}$ \\
\hline
\end{tabular}

\section{HASIL DAN PEMBAHASAN}

Dari poster yang disebar melalui media sosial, terdapat 117 nama yang mendaftar melalui google form. Jumlah peserta yang tercatat mengikuti penyuluhan daring tersebut sebanyak 77 dan jumlah peserta yang mengikuti pos tes sebanyak 98 orang. Terdapat perbedaan antara jumlah yang mengikuti penyuluhan daring dengan yang menjawab pos tes karena ada beberapa peserta bergabung dalam 1 layar Zoom. Hal ini diketahui waktu proses tanya jawab dan beberapa peserta dengan nama, dan nomor telepon selular (Whats App) yang berbeda tetapi menggunakan email yang sama.

Dari 98 peserta daring yang mengerjakan pos tes, sekitar 67 peserta (68\%) menjawab benar. Pada 3 jawaban terbaik, diberikan hadiah berupa pulsa telepon seluler sebesar 50 ribu Rupiah. Pertanyaan pos tesnya adalah: Sebutkan 3 contoh bahan makanan yang kurang baik untuk ABK yang hiperaktif?. Sembilan puluh satu peserta adalah wanita, berusia antara $26-58$ tahun, dan 7 peserta pria yang berusia $40-52$ tahun.

Jenis peserta terdiri dari orang tua ABK, orangtua non $\mathrm{ABK}$, pengasuh anak, guru $\mathrm{ABK}$, guru non $\mathrm{ABK}$, mahasiswa jurusan kesehatan dan lain-lain.
Tabel 2. Jenis Peserta Penyuluhan Daring

\begin{tabular}{|l|l|l|}
\hline No & Jenis Peserta & $\begin{array}{l}\text { Jumlah } \\
\text { (Persentase) }\end{array}$ \\
\hline 1. & Ortu ABK & $11(11 \%)$ \\
\hline 2. & Ortu non-ABK & $15(15 \%)$ \\
\hline 3. & Pengasuh anak & $10(10 \%)$ \\
\hline 4. & Guru ABK & $14(14 \%)$ \\
\hline 5. & Guru non-ABK & $8(8 \%)$ \\
\hline 6. & $\begin{array}{l}\text { Mahasiswa } \\
\text { kesehatan }\end{array}$ & $12(12 \%)$ \\
\hline 7. & Lain-lain & $28(29 \%)$ \\
\hline
\end{tabular}

Suasana sesi tanya jawab sangat interaktif. Untuk menambah antusiasme peserta, diberikan hadiah berupa pulsa telpon seluler sebesar 50 ribu Rupiah kepada 3 penanya terbaik. Peserta ada yang bertanya secara langsung, ada juga yang bertanya lewat chat yang dibacakan oleh moderator. Pertanyaan yang banyak ditanyakan adalah mengenai hal-hal praktis dalam kehidupan sehari-hari mengenai bagaimana menyusun menu untuk anak ABK hiperaktif, bagaimana mengatasi anak yang hanya suka satu jenis makanan saja, jajanan apa yang baik untuk anak hiperaktif dan beberapa pertanyaan lain seputar nutrisi.

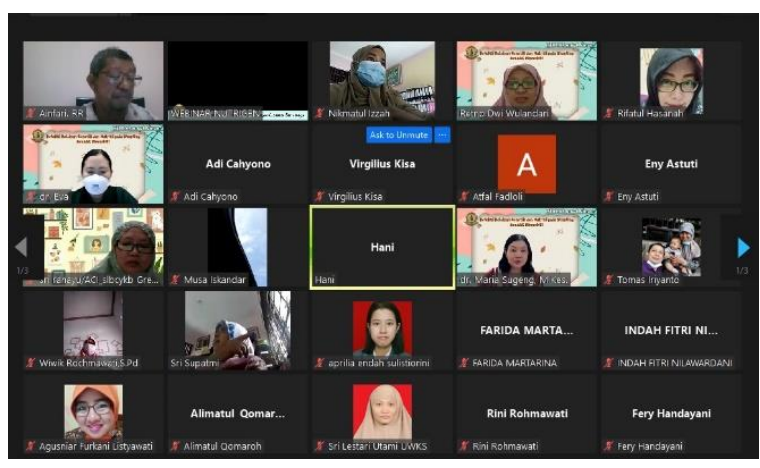

Gambar 1. Tampilan peserta daring pada Zoom 
1125 Penyuluhan Tentang Makanan yang Dianjurkan untuk Anak Berkebutuhan Khusus (ABK) Hiperaktif Maria Widijanti Sugeng, Retno Dwi Wulandari, Eva Diah Setijowati

DOI: https://doi.org/10.31004/abdidas.v2i5.424

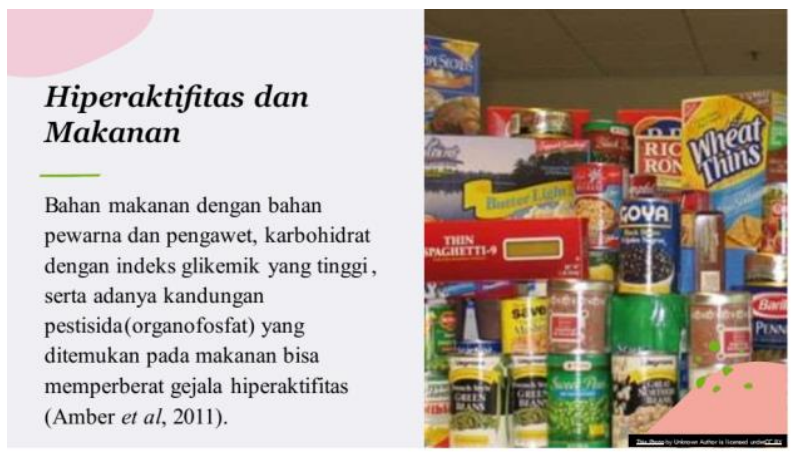

Gambar 2. Contoh slide persentasi

Semua peserta menjawab penyuluhan daring tentang nutrisi pada $\mathrm{ABK}$ hiperaktif ini bermanfaat.

\section{SIMPULAN}

Makanan yang mengandung artificial food additives seperti pewarna buatan, pengawet buatan dan tambahan rasa yang tidak natural, serta tinggi karbohidrat simpleks termasuk gula bisa meningkatkan hiperaktifitas dan gangguan konsentrasi pada anak-anak ABK dengan gejala hiperaktif.

Penyuluhan tentang makanan yang bisa mengurangi dan memperberat gejala hiperaktif akan sangat berguna bagi peserta, baik orang tua dengan anak ABK, orang tua biasa, guru SLB maupun tenaga kesehatan. Mereka pernah dan beberapa sering berhubungan dengan $\mathrm{ABK}$ dengan gejala hiperaktif, sehingga diharapkan mereka bisa meneruskan informasi mengenai nutrisi ini.

\section{UCAPAN TERIMA KASIH}

Ucapan terima kasih kami haturkan kepada Lembaga Penelitian dan Pengabdian Masyarakat (LPPM) Universitas Wijaya Kusuma Surabaya (UWKS) sebagai Pihak Penyandang Dana
Penyuluhan daring ini. Ucapan terima kasih juga kami haturkan kepada pihak Dekanat, Prodi dan Medical Education Unit (MEU) Fakultas Kedokteran UWKS yang mendukung semua proses terselenggaranya penyuluhan ini. Tidak lupa ucapan terima kasih juga kami berikan untuk ibu Rachel Nova Durita yang bertindak sebagai administrator dalam acara ini.

\section{DAFTAR PUSTAKA}

Barkley, R. A. (2014). Attention-Deficit Hyperactivity Disorder: A Handbook For Diagnosis And Treatment. Fourth. New York, NY: Guilford Press.

Cunningham, E. (2010). Are There Foods That Should Be Avoided If A Patient Is Sensitive To Salicylates? Journal of The American Dietetic Association, 110(6), 976.

Feingold, B. (1985). Why Your Child Is Hyperactive. Random House Incorporated.

Freeman, M. P., Hibbeln, J. R., Wisner, K. L., Davis, J. M., Mischoulon, D., Peet, M., Keck Jr, P. E., Marangell, L. B., Richardson, A. J., \& Lake, J. (2006). Omega-3 Fatty Acids: Evidence Basis For Treatment And Future Research In Psychiatry. Journal Of Clinical Psychiatry, 67(12), 1954.

Gray, P. E. A., Mehr, S., Katelaris, C. H., Wainstein, B. K., Star, A., Campbell, D., Joshi, P., Wong, M., Frankum, B., \& Keat, K. (2013). Salicylate Elimination Diets In Children: Is Food Restriction Supported By The Evidence? Medical Journal Of Australia, 198(11), 600-602.

Harrison, J. R., Bunford, N., Evans, S. W., \& Owens, J. S. (2013). Educational Accommodations For Students With Behavioral Challenges: A Systematic Review Of The Literature. Review of Educational Research, 83(4), 551-597.

Jones, T. W., Borg, W. P., Boulware, S. D., Mccarthy, G., Sherwin, R. S., \& Tamborlane, W. V. (1995). Enhanced Adrenomedullary Response And Increased Susceptibility To 
1126 Penyuluhan Tentang Makanan yang Dianjurkan untuk Anak Berkebutuhan Khusus (ABK) Hiperaktif Maria Widijanti Sugeng, Retno Dwi Wulandari, Eva Diah Setijowati

DOI: https://doi.org/10.31004/abdidas.v2i5.424

Neuroglycopenia: Mechanisms Underlying The Adverse Effects Of Sugar Ingestion In Healthy Children. The Journal Of Pediatrics, 126(2), 171-177.

Kane, P. (1999). Metabolic Assessment And Nutritional Biochemistry. Clinical And Research Aspects.

Lange, K. W. (2020). Micronutrients And Diets In The Treatment Of AttentionDeficit/Hyperactivity Disorder: Chances And Pitfalls. Frontiers In Psychiatry, 11, 102.

Mccann, D., Barrett, A., Cooper, A., Crumpler, D., Dalen, L., Grimshaw, K., Kitchin, E., Lok, K., Porteous, L., \& Prince, E. (2007). Food Additives And Hyperactive Behaviour In 3Year-Old And 8/9-Year-Old Children In The Community: A Randomised, DoubleBlinded, Placebo-Controlled Trial. The Lancet, 370(9598), 1560-1567.

Park, S.-M., Park, J. S., Park, H.-S., \& Park, C.-S. (2013). Unraveling The Genetic Basis Of Aspirin Hypersensitivity In Asthma Beyond Arachidonate Pathways. Allergy, Asthma \& Immunology Research, 5(5), 258-276.

Prinz, R. J., \& Riddle, D. B. (1986). Associations Between Nutrition And Behavior In 5-YearOld Children. Nutrition Reviews (USA).

Prinz, R. J., Roberts, W. A., \& Hantman, E. (1980). Dietary Correlates Of Hyperactive Behavior In Children. Journal Of Consulting And Clinical Psychology, 48(6), 760.

Schab, D. W., \& Trinh, N.-H. T. (2004). Do Artificial Food Colors Promote Hyperactivity In Children With Hyperactive Syndromes? A Meta-Analysis Of Double-Blind PlaceboControlled Trials. Journal of Developmental \& Behavioral Pediatrics, 25(6), 423-434.

Selhub, E. (2015). Nutritional Psychiatry: Your Brain On Food. Hardvard And Health Blog, 16(11), 2015.

Sharma, J. N., \& Mohammed, L. A. (2006). The Role Of Leukotrienes In The Pathophysiology Of Inflammatory Disorders: Is There A Case For Revisiting Leukotrienes As Therapeutic Targets? Inflammopharmacology, 14(1), 10-16.

Stevens, L. J., Zentall, S. S., Deck, J. L., Abate, M.
L., Watkins, B. A., Lipp, S. R., \& Burgess, J. R. (1995). Essential Fatty Acid Metabolism In Boys With Attention-Deficit Hyperactivity Disorder. The American Journal Of Clinical Nutrition, 62(4), 761-768. 